\title{
PHENOTYPIC CHARACTERIZATION OF GENETIC RESOURCES OF INDIGENOUS CATTLE IN WEST GONDAR ZONE OF ETHIOPIA
}

\author{
Eshet EMRU1, Solomon ABEGAZ², Addis GETU1 ${ }^{\circledR} \bowtie$, Araya MENGISTU1, Tewodros FANTAHUN1 \\ ${ }^{1}$ College of Veterinary Medicine and Animal sciences, University of Gondar, Ethiopia \\ 2 Gondar Agricultural Research Centre, Ethiopia \\ Email: bele23@gmail.com \\ Supporting Information
}

\begin{abstract}
This study was conducted to identify and phenotypic characterization of the existing indigenous cattle genetic resources in the three districts of West Gondar zone of Amhara Region based on their descriptive morphological characteristics. A total of six sampling sites were purposively selected based on the distribution of unique cattle types. Key informant and focus group discussions were used to identify the new genetic resources. A total of 180 adult male and 720 female cattle were selected for $\mathbf{2 0}$ morphological and 9 biometrical traits. The focus group discussions revealed that, diversified indigenous cattle were found (Fellata in Quara, Rutana in Metema, Miramir in West Armachiho and Qocherie from all Districts). The overall mean linear body measurements of male cattle for horn length, body length, heart girth, canon bone length and cannon bone circumferences were $23.92 \mathrm{~cm}, 127.97 \mathrm{~cm}, 161.15 \mathrm{~cm}, 20.37 \mathrm{~cm}$ and 19.81 respectively. Females had horn length $(25.86 \mathrm{~cm})$, body length $(122.85 \mathrm{~cm})$, pelvic width $(37.47 \mathrm{~cm})$ and canon bone length $(19.26 \mathrm{~cm})$, canon bone circumferences $(18.36 \mathrm{~cm})$ and mouth circumferences $(36 \mathrm{~cm})$. In a discriminate analysis, all sampled populations were classified with the overall hit rates of $75 \%$ for males and $60 \%$ for females. The shortest and longest mehalanobis distances were between Abrajira with Dubaba (0.762) and Gendawuha Birshign with Mirt Gelegu (37.88) for male and Gendawuha Birshign with Dubaba (0.358) and Gendawuha Birshign with Mirt Gelegu (29.37) for females, respectively. In stepwise discriminate analysis the top traits which were highly discriminated male cattle populations were cannon bone length, horn length and cannon bone circumferences. This was similar in females except the replacement of cannon bone circumferences with mouth circumferences. Three clusters were formed (Fellata from Mirt Gelegu in cluster one and Qocherie from Gendawuha Birshign, Dubaba and Abrajira in cluster two and Rutta from Lominat Forgena and Miramir from Gilal Wuha in cluster three. Three indigenous cattle types were identified with their phenotypic features and further molecular characterization should be done to confirm their genetic distinctiveness.
\end{abstract}

Keywords: Cattle, Characterization, Genetic Resources, Phenotype, West Gondar Region.

\section{INTRODUCTION}

Ethiopia is rich in animal genetic resources both in diversity and population number in Africa (Endashaw, 2010). The current national estimated number of livestock population except for the three zones of Afar and six zones of Somali region; 59.5 million cattle, 30.7 million sheep 30.2 million goat, 1.21 million camel, 56.53 million poultry, 2.16 million horses, 0.41 million mules and 8.44 million donkeys (CSA, 2017). According to FAO (2010) at the level of national economy average livestock production contributes about $30-35 \%$ of agricultural gross domestic product (GDP) and 1-16\% of the overall national GDP. The same source indicated that cattle have the highest figure and most important sources which contributed about 35\% in agricultural GDP and 15\% in total GDP. Among livestock population, cattle contribute a lot to improve the wellbeing of the farm family through food supply, balancing nutrition, income, savings, insurance, ritual and other social purposes.

The contribution of livestock to the country's economy is too low when compared with the population size. This might be due to weak estimation methodology or weak analysis of economic values of livestock products and poor plane of nutrition, prevalence of disease and lack of appropriate breeding strategies (Mezgebe et al., 2018; Sasaki et al., 2019). To divert this challenges; identification and phenotypic characterization of cattle genetic resources are necessary in order to develop breed improvement programs (FAO, 2007). However, based on the previous work at national level, there is insufficient information about breed characterization at phenotypic and genetic levels (DAGRIS, 2009; Kemp et al., 2007). Similarly, no one has conducted a research work on phenotypic characterization of cattle genetic resources in the border of Sudan in the Western part of West Gondar zone. Therefore, with this gap the specific objective was initiated to identify and phenotypically characterize cattle genetic resources in West Gondar zone, Amhara Region, Ethiopia.

\section{MATERIAL AND METHODS}

\section{Description of the study area}

The study was conducted in the three districts namely Quara, Metema and West Armachiho of West Gondar zone. Exploratory approach and purposive sampling techniques were used to characterize the unique and diversified cattle 
population in the zone. To know the distribution of cattle genetic resources and establish the sampling frame, rapid preliminary survey and discussions were held with zonal, district and rural development agents of livestock experts. Based on the information, six representative sites were purposively selected. Sampling frame, from each mature age cattle breed types $n=150$ (30 males and 120 females) were randomly selected for administration of morphological and biometrical measurements (FAO, 2012). Therefore, a total of 180 male and 720 female cattle were randomly selected for phenotypic characterization.

\section{Data types}

Twenty categorical traits were recorded and documented from live adult cattle by visual observation and nine quantitative traits were considered and measured using mark off measuring tape in $\mathrm{cm}$ with a precision of 0.5 from cattle with wear off one and above pair of permanent teeth (FAO, 2012).

\section{Data analysis}

Univarite analysis. General linear model procedures (PROC GLM) were employed for quantitative variables to detect statistical differences among sample cattle population. The model was developed to evaluate the linear body measurements with the fixed effect of sex and sites.

$$
\mathrm{Y}_{\mathrm{jk}}=\mu+\mathrm{S}_{\mathrm{j}}+\mathrm{L}_{\mathrm{k}}+\mathrm{e}_{\mathrm{jk}}
$$

Yjk: Linear body measurements in each the $j^{\text {th }}$ sex and $k^{\text {th }}$ location; $\mu$ : Overall mean, for both sexes separately; $S_{j}$ : the effect of $j^{\text {th }} \operatorname{sex}\left(j: 1=\right.$ male, 2= female); $L_{k}$ : the effect of $k^{\text {th }}$ location ( $k$ : 1=Dubaba, 2=Mirt Gelegu, 3=G.Birshign, 4=Lominat Forgena, 5=Abrajira, 6=Gilal Wuha); e jk: residual random error associated with $_{\mathrm{jk}}{ }^{\text {th }}$ observation.

\section{Multivariate analysis}

Quantitative variables from male and female animals were separately subjected to discriminate analysis (PROC DISCRIM) to classify the sampled populations into homogenous/distinct breeds as a breed in their home areas. Procedure of canonical discriminate analysis (PROC CANDISC) was used to determine the existence of population level phenotypic differences among the sample cattle populations/the study sites. The step wise discriminate analysis procedure (PROC STEP DISC) was used and run to rank the variables by their discriminating power. Correspondence analyses were considered for association of different categorical variables for each study sites/cattle population. Finally, to classify the sampled cattle population cluster analysis were carried out by using quantitative variables and then classification trees were constructed based on results of the analysis and showed groups of the identified breed types.

\section{RESULT AND DISCUSSION}

\section{Univarite analysis}

Quantitative Variation for male population. Almost all continuous variables were highly significant $(p<0.0001)$ and affected by site except ear length ( $p<0.99$; Table 1 ). This might be due to the study areas were occupied by different breed types with varied quantitative traits. The smallest and highest coefficient of determination $\left(R^{2}\right)$ was calculated for ear length and for heart girth, respectively. Whereas, for the coefficient of variation (CV) was heart girth and horn length, respectively. The least square means comparison among the study sites revealed that male population from Gilal Wuha, Lominat Forgena and Mirt Gelegu had the largest values than the remaining sites for most variables. While, the lower least square mean values were obtained from the remaining three sites (Dubaba, Gendawuha Birshign and Abrajira).

Quantitative variation for female population. Like male population except ear length all sampled continuous variables were highly significant $(p<0.0001)$ for sample sites of female cattle population (Table 2). The coefficients of variation ranged from $2.39 \%$ for heart girth to $34.9 \%$ for horn length. Traits which had high coefficient values were possible for source of variation in the population. The highest least square mean values for most measurable traits in female sampled population were observed in Gilal Wuha, Lominat Forgena and Mirt Gelegu sites. This indicated that the cattle type from these sites had phenotypic superiority than the remaining site cattle types. This agrees with Monastery and Begait cattle type documented by Zewdu (2004); Mulugeta (2015), respectively. Conversely, the lowest least square mean values were recorded from Dubaba, Gendawuha Birshign and Abrajira. These three sites had almost similar measurement values. This might be due to their continual interbreeding or same phenotypic features. These findings are similar with Zewdu (2004), Fasil (2006); Tadesse (2015) who reported for North Gondar lowland, Gojjam highland and Horro cattle types, respectively.

\section{Multivariate analysis}

Discriminate analysis. The correct classification percentages for male population were ranged from $46.67 \%$ to 93.33\% for site 1 (Dubaba) and site 2 (Mirt Gelegu), respectively. The remaining reclassification values of Dubaba were explained in Gendawuha Birshign (16.67\%) and Abrajira (36.67\%) sites. This indicated that males from Dubaba were shared high number of cross classification hit rates with Gendawha Birshign and Abrajira sites. Among the study sites male cattle population from Mirt Gelegu scored the highest classification percentages (93.33\%). This indicated that male cattle from Mirt Gelegu were more heterogeneous and distinct from other site population. Similarly, male cattle 
population in Lominat Forgena had correct classification of $76.67 \%$ in their sites and the incorrect classification (23.33\%) was explained in Gilal Wuha location. This revealed that males from these sites had common characteristics. The overall correct and incorrect classification percentages of male populations in all the study sites were $75 \%$ and $25 \%$, respectively. This correct hit rate classification higher than (Zewdu, 2004) for north Gondar cattle (73.8\%) but lower (Tadesse, 2005) for Horro cattle (82.72\%) and (Fasil, 2006) for Gojjam highland cattle (80.85\%), respectively. Similarly, the correct classification percentages of female sampled population for all sites were ranged from Gendawuha Birshign (42.5\%) to Mirt Gelegu (98.33\%) sites. The remaining classification percentages of Gendawuha Birshign sites were incorrectly classified in Dubaba (23.33\%), Abrajira (33.33\%) sites. Correspondingly, the correct and incorrect classification values of female population from Lominat Forgena were $\mathbf{4 7 . 5 \%}$ and $37.5 \%$, respectively. This incorrect classification percentage was explained in Gilal Wuha. This indicated that the two sites had similar phenotypic features. The overall correct classification hit rates for female sample population were $60 \%$. The overall error count estimation in male sample population was better than female population (as the average hit rate was $75 \%$ than $60 \%$ ).

Canonical discriminate analysis. It was performed by CANDISC procedures separately for male and female sample population. As per Table 5, all mahalanobis distances obtained from the sites for male population were highly significant $(p<0.0001)$. Therefore, male population from each site has their own measurable differences. The nearest distances were observed in Abrajira and Dubaba sites with the value of 0.76185 . This might be due to the two sites had phenotypically similar male cattle population. Whereas, the longest distances (37.88) was observed between Gendawuha Birshign and Mirt Gelegu sites. Therefore, these two sites had their own distinct and different male cattle types. In case of female sample population, the Mahalanobis distance between sites was slightly lower than that of male population. Mahalanobis distances obtained for female population was significant for all sites. The nearest distance was observed in between Gendawuha Birshign and Dubaba followed by Abrajira and Gendawuha Birshign with the values of 0.35833 and 0.51030 , respectively. The largest distance was observed between site 3 (Gendawuha Birshign) and site 2 (Mirt Gelegu) with the value of 29.38. The narrower and wider differences were resulted from phenotypic similarities and disparities between the sample populations.

Stepwise discriminate analysis. All 9 continuous variables for both sexes were separately subjected to the STEPDISC procedure of (SAS, 9.4) and all 9 variables for males and 8 variables for females were identified as best discriminating variables (Table 7). Variables used for discriminating male breed types were ordered based on their discriminating powers namely cannon bone length, horn length, cannon bone circumferences and body length. Similarly, top variables, which discriminate female population, were cannon bone length, horn length, mouth circumferences, body length, ear length, and cannon bone circumferences. Whereas, height at wither was weak for separating female sample population and was removed.

Correspondence analysis for qualitative variables. Twenty different categorical variables for all the study sites were considered for correspondence analysis (Figure 1). Two dimensions were observed for the clear relationships of the traits with study sites. Categorical variable lies on the middle line were predominantly found in all the population and represented low variation among the population. Small hump size, and lateral ear orientation in (sites 1 and 2 ) and, erect horn shape, convex facial profile, medium hump size and medium body condition both in site 3, 5 and site 4, 6 had very close to the middle line. And, for all population large tail length, medium body condition score, sloppy rump profile, short and curved horn shape and black white color variables represented very low variations. Whereas, categorical variables far from the middle line were distinguished the 6 studied populations namely coat color type, navel flap, dewlap width, udder size and teat length in one hand and the genetic groups were in the other hands.

Cluster analysis. Cluster analysis is a multivariate technique used to group individuals based on common characteristics in to homogeneous and distinct groups (Peter, 1997). Due to this; the population in one cluster shared certain common characters more than the population in other cluster. According to cluster analysis 3 similar clusters were formed for both sexes in figure 2. Hence, the first cluster consisted of sample population of site 2 (Mirt Gelegu) which, represent Fellata cattle type, came out distinctly far from the rest group breed types in both cases. The second cluster contained three sites namely; site 1 (Dubaba), site 3 (Gendawuha Birshign) and site 5 (Abrajira). Moreover, the cattle type from site 4 (Lominat Forgena) and site 6 (Gilal Wuha) grouped under the third clusters.

Cluster 1: Fellata cattle type. This cattle type is unique in many aspects from the rest of the population. They are aggressive in their temperament and large in body size. Their coat colour pattern is plain (76.0\%) and patchy (14.7\%) and spotted (9.3\%). The hair types were shiny (69.3\%) with dull (26.0\%) and smooth (9.3\%). Most of the animals have exceptionally longer horns $(50.95 \mathrm{~cm}$ in females and $47.06 \mathrm{~cm}$ in males) with white in colour and lyre (54\%), curved (26.7\%) and straight (19.3\%) in its shape. Mostly flat (58\%) facial profiles were observed in both sexes and rarely concave with thin neck in females and regularly convex in males. Ear is medium to big in size with mainly straight and pendulous shapes. Humps and dewlaps are well developed in males with good height at wither but small humps with erected shapes and almost non dewlaps in females (their unique features). Body condition scoring of this cattle was medium (78.7\%), lean (16.0\%) and fat (5.3\%) in both sexes. Tail is medium to long in females and long with bushy ends in males; important for prevention of wild flies. Cows have longer navel length, large udder and teat size of all the breed types in the study location. These characteristics were considered for selection criteria in the study location. Similarly, perpetual sheath and testicular lengths are very long in males. These traits were also highly considered in the communities for selection criteria's of breeding bull. These cattle types mainly serve for the community through reproduction, milk production and 
for income generation, and draft power. According to key informants; this cattle type is believed to be found only in Quara district of specific location.

Cluster 2: Qocherie /Korrer cattle type. These are medium body size cattle types with good temperament. Their coat colors are dominantly plain of red, white, black, grey and patchy of black brown, with a very small proportion of spotted of red white, white and red sora pattern and types, respectively. Their facial profile is dominantly concave in females and convex in males with moderate ear length of straight and slightly pendulous in shapes and forward, lateral in orientation. In both sexes, horns are medium to large in size; straight, curved in shapes with forward and upward in orientation. Hump and dewlap sizes are relatively large in males with moderate heart girth and small to medium size in females. They have small to medium length of navel flap with medium to large udder and teat size with good taste of milk. Perpetual sheath and testicular circumferences are medium to large in males. Tail is dominantly medium to long in its length in females and long (below hocks) in males. As group discussants revealed that main attributes of these cattle types are milk production, reproduction and income purposes. Based on the above characteristics these dominant Qocherie cattle types are grouped under Small East African Zebu cattle types.

Cluster 3: Ruttana/Miramir cattle type. They are huge in body size when compared with other cattle types and able to communicate with language. These cattle types are almost similar with the characteristics of large East African Zebu and not documented in literature as Rutana/Miramir cattle in the country. They are aggressive in temper but it is desired by their owners (cannot be stolen by theft). Their coat color pattern is spotted and patchy composed of white- black, blackwhite and gray type; rarely plain of black, white and grey. Mostly they have shiny, dull and the rest smooth hair types. Horns are medium to large in both sexes with straight, curved and lyre shapes and some cattle also have no horns. Females' have predominately flat and slightly concave facial profile and male have convex profiles. Ear is medium to large in size and mainly straight shapes and they are good in body conformation and scored mainly medium and rarely fat condition with droopy, sloppy and flat rumps. Hump sizes are small to medium in females and well developed in males with commonly erected and droopy shapes with cervico-thoracic in its position. Similarly, dewlap sizes are large in males but very small in females. These cattle types are known with longest sheath and testicular circumferences. Medium to large udder and teat size and long navel flaps. Majorities have long tail length and in small proportion has medium lengths. Milk, reproduction, income generation, traction power and beef are among the most important of functions of this cattle type. According to key informants Rutana-Miramir cattle types are found only in specific location of Metema and West Armachiho districts border to Sudan, respectively. Except body size (little big in Miramir), name of cattle type and their location, all the rest characters are almost similar in phenotype for these cattle type and grouped under one cluster. As per the above, characteristics indicated that these cattle types are a unique.

Table 1 - Least square means and pair wise comparisons of body measurements for males by site (cm)

\begin{tabular}{lccccccccc} 
Variables & Dubaba & M.G & G.B & L.F & Abrajira & G.Wuha & R $^{2}$ & CV & Site \\
\hline Horn length & $18.81^{\mathrm{b}}$ & $47.06^{\mathrm{a}}$ & $16.41^{\mathrm{b}}$ & $21.28^{\mathrm{b}}$ & $17.48^{\mathrm{b}}$ & $22.51^{\mathrm{b}}$ & 64.32 & 33.3 & $\mathrm{p}<.0001$ \\
Ear length & $22.12^{\mathrm{a}}$ & $22.02^{\mathrm{a}}$ & $20.99^{\mathrm{a}}$ & $21.75^{\mathrm{a}}$ & $22.17^{\mathrm{a}}$ & $22.34^{\mathrm{a}}$ & $\mathbf{4 0 . 4 8}$ & 5.52 & 0.999 \\
Body length & $119.41^{\mathrm{b}}$ & $136.41^{\mathrm{a}}$ & $117.63^{\mathrm{b}}$ & $138.37^{\mathrm{a}}$ & $117.84^{\mathrm{b}}$ & $138.15^{\mathrm{a}}$ & 83.70 & 3.97 & $\mathrm{p}<.0001$ \\
Height W. & $113.38^{\mathrm{b}}$ & $132.53^{\mathrm{a}}$ & $110.19^{\mathrm{b}}$ & $135.23^{\mathrm{a}}$ & $114.26^{\mathrm{b}}$ & $136.49^{\mathrm{a}}$ & $\mathbf{8 0 . 8 9}$ & 5.05 & $\mathrm{p}<.0001$ \\
Canon BL & $16.64^{\mathrm{b}}$ & $24.59^{\mathrm{a}}$ & $16.17^{\mathrm{b}}$ & $23.47^{\mathrm{a}}$ & $16.83^{\mathrm{b}}$ & $24.53^{\mathrm{a}}$ & 79.98 & 9.88 & $\mathrm{p}<.0001$ \\
Canon BC & $16.64^{\mathrm{b}}$ & $22.26^{\mathrm{a}}$ & $17.42^{\mathrm{b}}$ & $22.64^{\mathrm{a}}$ & $16.19^{\mathrm{b}}$ & $23.69^{\mathrm{a}}$ & 77.09 & 9.17 & $\mathrm{p}<.0001$ \\
Mouth C & $38.63^{\mathrm{b}}$ & $39.89^{\mathrm{ab}}$ & $38.64^{\mathrm{b}}$ & $39.85^{\mathrm{b}}$ & $38.71^{\mathrm{b}}$ & $41.42^{\mathrm{a}}$ & 55.78 & 5.04 & $\mathrm{p}<.0001$ \\
Pelvic width & $35.71^{\mathrm{b}}$ & $41.16^{\mathrm{a}}$ & $36.70^{\mathrm{b}}$ & $41.51^{\mathrm{a}}$ & $36.56^{\mathrm{b}}$ & $4^{\mathrm{b} .20^{\mathrm{a}}}$ & 70.16 & 5.46 & $\mathrm{p}<.0001$ \\
Heart girth & $151.98^{\mathrm{b}}$ & $170.48^{\mathrm{a}}$ & $148.86^{\mathrm{b}}$ & $172.94^{\mathrm{a}}$ & $152.35^{\mathrm{b}}$ & $170.32^{\mathrm{a}}$ & 85.49 & 3.28 & $\mathrm{p}<.0001$
\end{tabular}

a.b.c.e.f Means with the same superscript letter on the same row are not significantly different, $\mathrm{R}^{2}=$ Coefficient of determination, $\mathrm{CV}=\mathrm{Coefficient}$ of Variation; M.G= Mirt gelegu, G.B=Gendawuha Birshign and L.F=Lominat forgena.

Table 2 - Least square means and pair wise comparisons of body measurements for females by site (cm)

\begin{tabular}{|c|c|c|c|c|c|c|c|c|c|}
\hline Variables & Dubaba & M.G & G.B & L.F & Abrajira & G.wuha & $\mathbf{R}^{2}$ & CV & Site \\
\hline Horn length & $20.63^{b}$ & $50.95^{a}$ & $20.95^{b}$ & $19.75^{b}$ & $19.92^{b}$ & $22.97^{b}$ & 62.92 & 34.9 & $p<.0001$ \\
\hline Ear length & $21.23^{a}$ & $21.03^{a}$ & $21.51^{a}$ & $21.22^{a}$ & $21.13^{a}$ & $21.56^{a}$ & 42.02 & 6.22 & 0.999 \\
\hline Body length & $116.63^{b}$ & $129.79^{a}$ & $116.65^{b}$ & $127.90^{a}$ & $114.82^{\mathrm{b}}$ & $130.49^{a}$ & 74.21 & 4.03 & $p<.0001$ \\
\hline Wither Height & $110.83^{b}$ & $122.65^{a}$ & $110.32^{b}$ & $121.33^{a}$ & $108.81^{b}$ & $124.17^{a}$ & 68.48 & 4.85 & $p<.0001$ \\
\hline Canon BL & $17.07^{c}$ & $22.26^{a}$ & $16.47^{c}$ & $21.31^{b}$ & $16.32^{c}$ & $22.13^{\mathrm{ab}}$ & 78.71 & 8.00 & $p<.0001$ \\
\hline Canon BC & $16.46^{b}$ & $20.41^{a}$ & $16.03^{b c}$ & $20.64^{a}$ & $15.36^{c}$ & $21.36^{a}$ & 76.20 & 8.47 & $p<.0001$ \\
\hline Mouth C. & $36.35^{\mathrm{ab}}$ & $34.51^{c}$ & $36.52^{b}$ & $36.16^{b}$ & $35.71^{b}$ & $36.78^{a}$ & 44.31 & 4.97 & $p<.0001$ \\
\hline pelvic width & $35.63^{b}$ & $38.49^{a}$ & $36.15^{b}$ & $38.98^{a}$ & $36.16^{b}$ & $39.42^{a}$ & 64.43 & 5.65 & $p<.0001$ \\
\hline Heart girth & $148.61^{d}$ & $152.32^{c}$ & $147.57^{d}$ & $155.03^{b}$ & $147.57^{d}$ & $157.29^{a}$ & 79.74 & 2.39 & $p<.0001$ \\
\hline
\end{tabular}


Table 3 - Number of observation and percentages (in bracket) for male sample population using discriminant analysis in each study sites

\begin{tabular}{lccccccc} 
Site & Dubaba & M.Gelegu & G.Birshig & L.Fogena & Abrajira & G.Wuha & Total \\
\hline Dubaba & $14(46.67)$ & 0 & $5(16.67)$ & 0 & $11(36.67)$ & 0 & $30(100)$ \\
M.G & 0 & $28(93.33)$ & 0 & $1(3.33)$ & 0 & $1(3.33)$ & $30(100)$ \\
G.B & $2(6.67)$ & 0 & $24(80.00)$ & 0 & $4(13.33)$ & 0 & $30(100)$ \\
L.F & 0 & 0 & 0 & $23(76.67)$ & 0 & $7(23.33)$ & $30(100)$ \\
Abrajira & $4(13.33)$ & 0 & $2(6.67)$ & 0 & $24(80.00)$ & 0 & $30(100)$ \\
G.Wuha & 0 & 0 & 0 & $8(26.67)$ & 0 & $22(73.33)$ & $30(100)$ \\
*TECE & 0.5333 & 0.0667 & 0.2000 & 0.2333 & 0.2000 & 0.2667 & $25(100)$
\end{tabular}

M.G=Mirt Gelegu, G.B=Gendawuha Birshign, L.F=Lominat Forgena, G.W=Gilal Wuha and*TECE=total error count estimate.

\begin{tabular}{|c|c|c|c|c|c|c|c|}
\hline Sites & Dubaba & M.Gelegu & G.Birshign & L.Fogena & Abrajira & G.Wuha & Total \\
\hline Dubaba & $56(46.67)$ & 0 & $33(27.5)$ & $3(2.5)$ & $28(23.33)$ & 0 & $120(100)$ \\
\hline M.G & $1(0.83)$ & $118(98.33)$ & 0 & $1(0.83)$ & 0 & 0 & $120(100)$ \\
\hline $\begin{array}{l}\text { G.B } \\
\text { L.F }\end{array}$ & $\begin{array}{l}28(23.33) \\
12(10.00)\end{array}$ & $\begin{array}{l}1(0.83) \\
1(0.83)\end{array}$ & $\begin{array}{c}51(42.50) \\
3(2.50)\end{array}$ & $\begin{array}{c}0 \\
57(47.50)\end{array}$ & $\begin{array}{c}40(33.33) \\
2(1.67)\end{array}$ & $\begin{array}{c}0 \\
45(37.50)\end{array}$ & $\begin{array}{l}120(100) \\
120(100)\end{array}$ \\
\hline Abrajira & $29(24.17)$ & 0 & $24(20.00)$ & $1(0.83)$ & $66(55.00)$ & 0 & $120(100)$ \\
\hline G.Wuha & $1(0.83)$ & $2(1.67)$ & $1(0.83)$ & $32(26.67)$ & 0 & $84(70.00)$ & $120(100)$ \\
\hline *TECE & 0.5333 & 0.0167 & 0.5750 & 0.5250 & 0.4500 & 0.3000 & $40(100)$ \\
\hline
\end{tabular}

Table 5 - Mahalanobis distances between sites for male sample population

\begin{tabular}{|c|c|c|c|c|c|c|}
\hline Sites & Dubaba & M.Gelegu & G.Bishign & L.Forgena & Abrajira & G.Wuha \\
\hline Dubaba & $\star * *$ & & & & & \\
\hline M.Gelegu & 34.52597 & $* * *$ & & & & \\
\hline G.Bishign & 2.77802 & 37.88397 & $* * *$ & & & \\
\hline $\begin{array}{l}\text { L.forgena } \\
\text { Abrajira }\end{array}$ & $\begin{array}{c}31.35831 \\
0.76185\end{array}$ & $\begin{array}{l}14.73973 \\
35.01792\end{array}$ & $\begin{array}{c}29.23378 \\
4.28409\end{array}$ & $\begin{array}{c}* * * \\
31.60054\end{array}$ & $* * *$ & \\
\hline G.Wuha & 30.62582 & 14.68674 & 27.05451 & 2.28319 & 30.97339 & $* * *$ \\
\hline
\end{tabular}

Table 6 - Mahalanobis distances between sites for female sample population

\begin{tabular}{|c|c|c|c|c|c|c|}
\hline Sites & Dubaba & M.Gelegu & G.Bishign & L.forgena & Abrajira & G.Wuha \\
\hline Dubaba & $\star * *$ & & & & & \\
\hline M.Gelegu & 25.76750 & $\star * *$ & & & & \\
\hline G.Bishign & 0.35833 & 29.37554 & $\star * *$ & & & \\
\hline L.forgena & 11.26041 & 15.30541 & 14.40911 & $* * *$ & & \\
\hline Abrajira & 0.92079 & 28.48766 & 0.51030 & 14.51182 & $\star \star *$ & \\
\hline G.Wuha & 14.53294 & 14.26129 & 18.27180 & 0.58177 & 18.33785 & $\star * *$ \\
\hline
\end{tabular}

\begin{tabular}{|c|c|c|c|c|c|c|c|c|c|}
\hline \multicolumn{2}{|c|}{$\begin{array}{l}\text { Steps in discriminating } \\
\text { power }\end{array}$} & $\begin{array}{l}\text { Entered } \\
\text { Traits }\end{array}$ & $\begin{array}{c}\text { Partial } \\
\mathbf{R}^{2}\end{array}$ & F-statistics & $\operatorname{Pr}>\mathrm{F}$ & $\begin{array}{c}\text { Wilks' } \\
\text { Lambda }\end{array}$ & $\begin{array}{c}\text { Pr< } \\
\text { Lambda }\end{array}$ & $\begin{array}{c}\text { Average Squared } \\
\text { Canonical Correlation }\end{array}$ & Pr>ASCC \\
\hline \multirow{9}{*}{$\begin{array}{l}\text { Male } \\
\text { population }\end{array}$} & 1 & CBL & 0.763 & 112.17 & $<.0001$ & 0.237 & $<.0001$ & 0.153 & $<.0001$ \\
\hline & 2 & HL & 0.488 & 32.93 & $<.0001$ & 0.121 & $<.0001$ & 0.244 & $<.0001$ \\
\hline & 3 & СВC & 0.329 & 16.87 & $<.0001$ & 0.081 & $<.0001$ & 0.298 & $<.0001$ \\
\hline & 4 & $\mathrm{BL}$ & 0.289 & 13.96 & $<.0001$ & 0.058 & $<.0001$ & 0.323 & $<.0001$ \\
\hline & 5 & EL & 0.264 & 12.17 & $<.0001$ & 0.043 & $<.0001$ & 0.336 & $<.0001$ \\
\hline & 6 & HW & 0.121 & 4.67 & 0.0005 & 0.037 & $<.0001$ & 0.349 & $<.0001$ \\
\hline & 7 & $H G$ & 0.102 & 3.81 & 0.0027 & 0.034 & $<.0001$ & 0.367 & $<.0001$ \\
\hline & 8 & PW & 0.099 & 3.71 & 0.0033 & 0.030 & $<.0001$ & 0.383 & $<.0001$ \\
\hline & 9 & $\mathrm{MC}$ & 0.082 & 2.96 & 0.0138 & 0.028 & $<.0001$ & 0.389 & $<.0001$ \\
\hline \multirow{8}{*}{$\begin{array}{l}\text { Female } \\
\text { population }\end{array}$} & 1 & CBL & 0.71 & 349.9 & $<.0001$ & 0.299 & $<.0001$ & 0.142 & $<.0001$ \\
\hline & 2 & HL & 0.52 & 153.87 & $<.0001$ & 0.139 & $<.0001$ & 0.245 & $<.0001$ \\
\hline & 3 & MC & 0.25 & 46.72 & $<.0001$ & 0.105 & $<.0001$ & 0.266 & $<.0001$ \\
\hline & 4 & $\mathrm{BL}$ & 0.12 & 19.94 & $<.0001$ & 0.092 & $<.0001$ & 0.274 & $<.0001$ \\
\hline & 5 & EL & 0.099 & 15.73 & $<.0001$ & 0.083 & $<.0001$ & 0.279 & $<.0001$ \\
\hline & 6 & CBC & 0.093 & 14.45 & $<.0001$ & 0.075 & $<.0001$ & 0.289 & $<.0001$ \\
\hline & 7 & PW & 0.048 & 7.12 & $<.0001$ & 0.071 & $<.0001$ & 0.298 & $<.0001$ \\
\hline & 8 & HG & 0.016 & 2.34 & 0.0402 & 0.070 & $<.0001$ & 0.299 & $<.0001$ \\
\hline
\end{tabular}




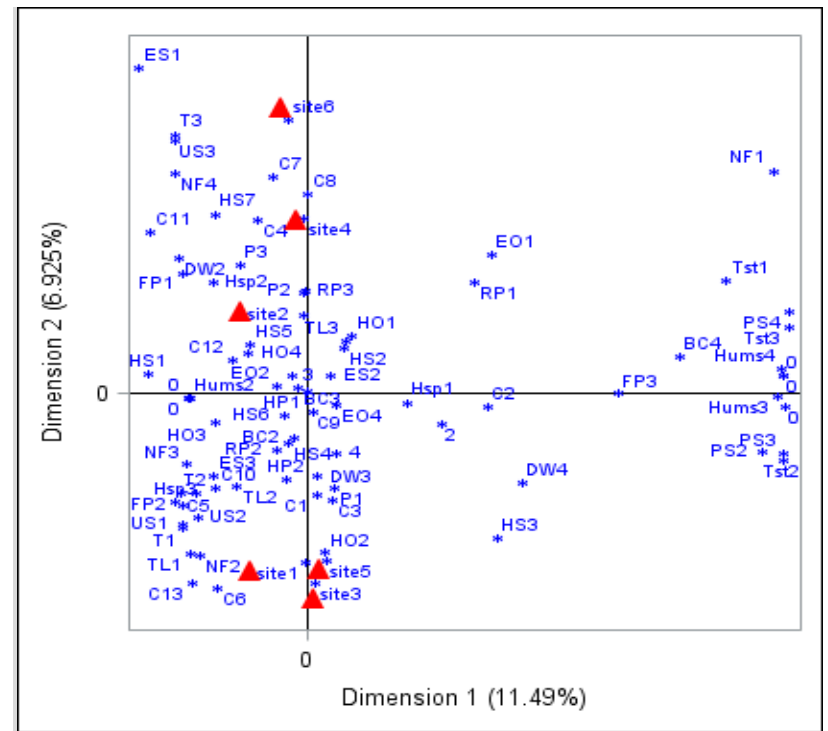

Figure 1- Associations among qualitative variables revealed by multiple correspondence analyses.

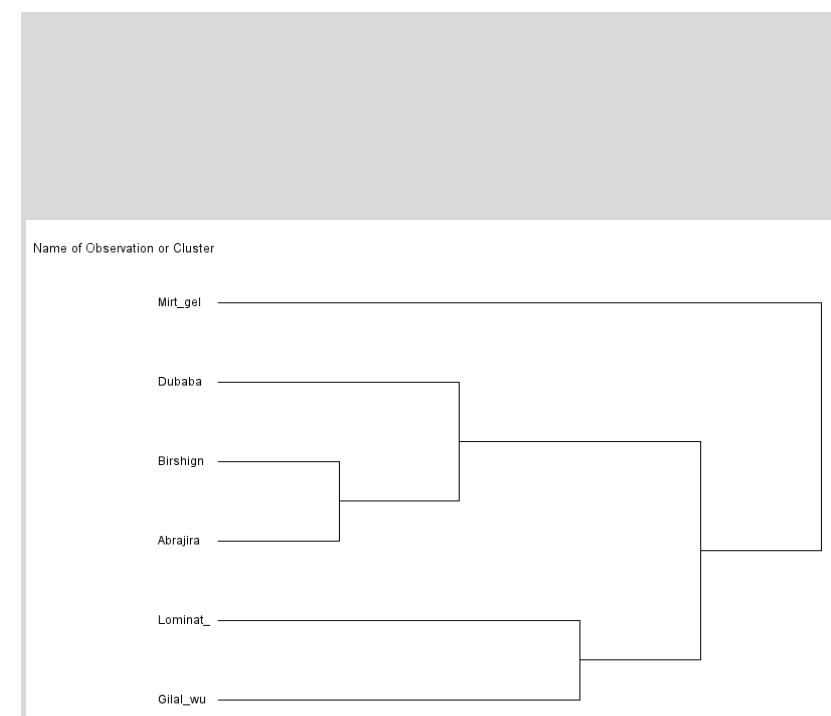

Figure 2 - Cluster trees for cattle population by study site.
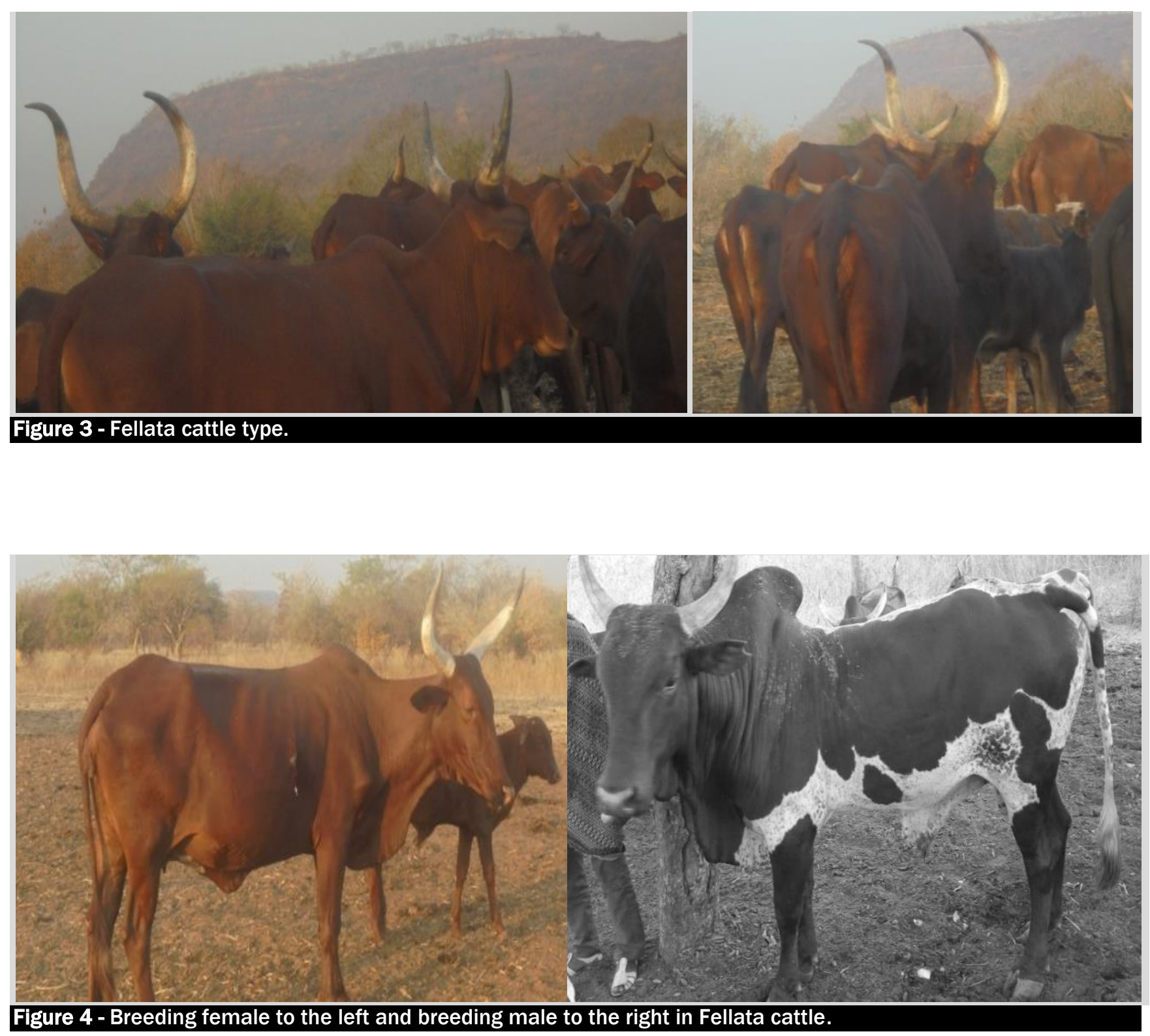


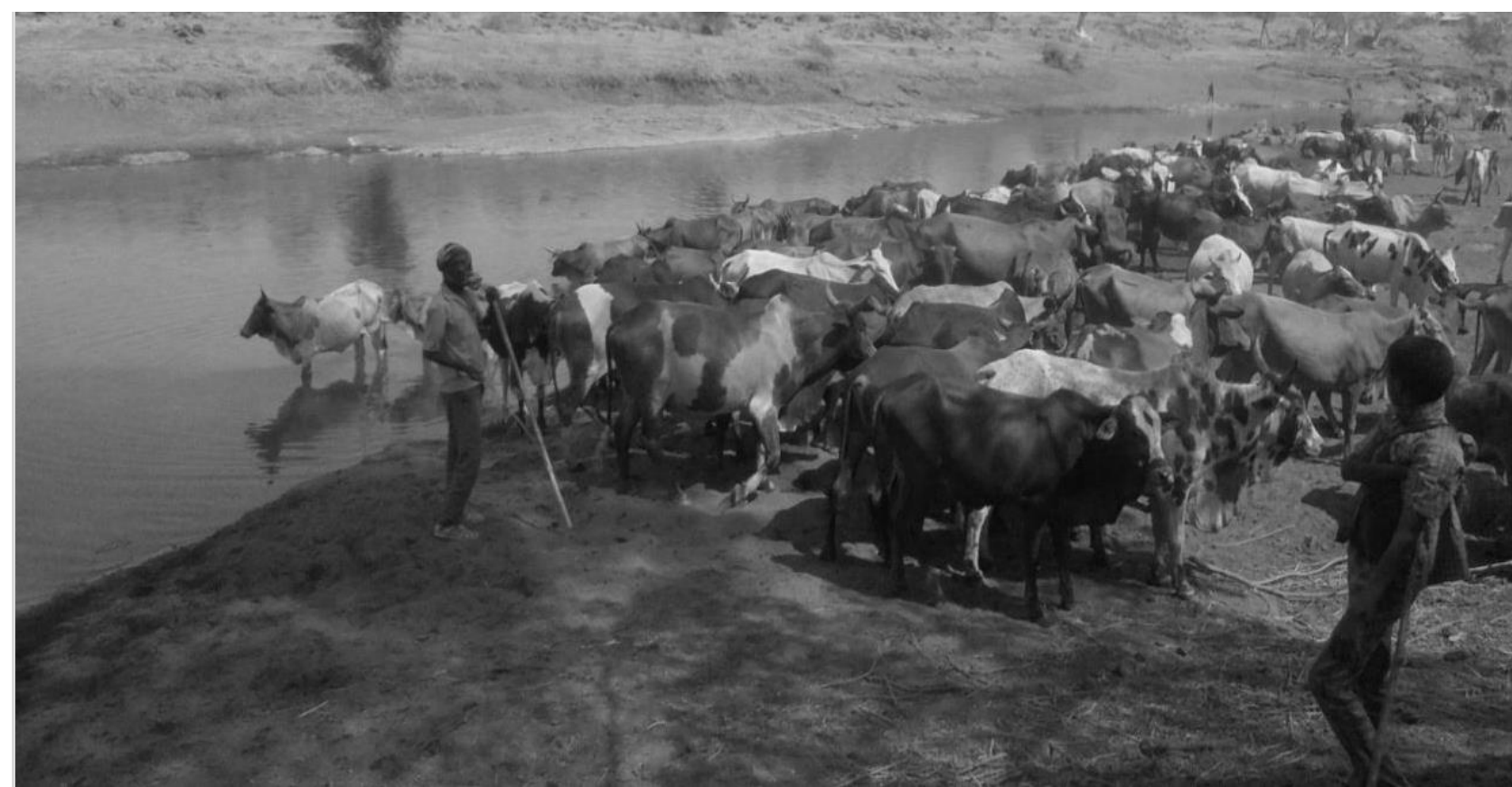

Figure 5 - Qocherie cattle type.

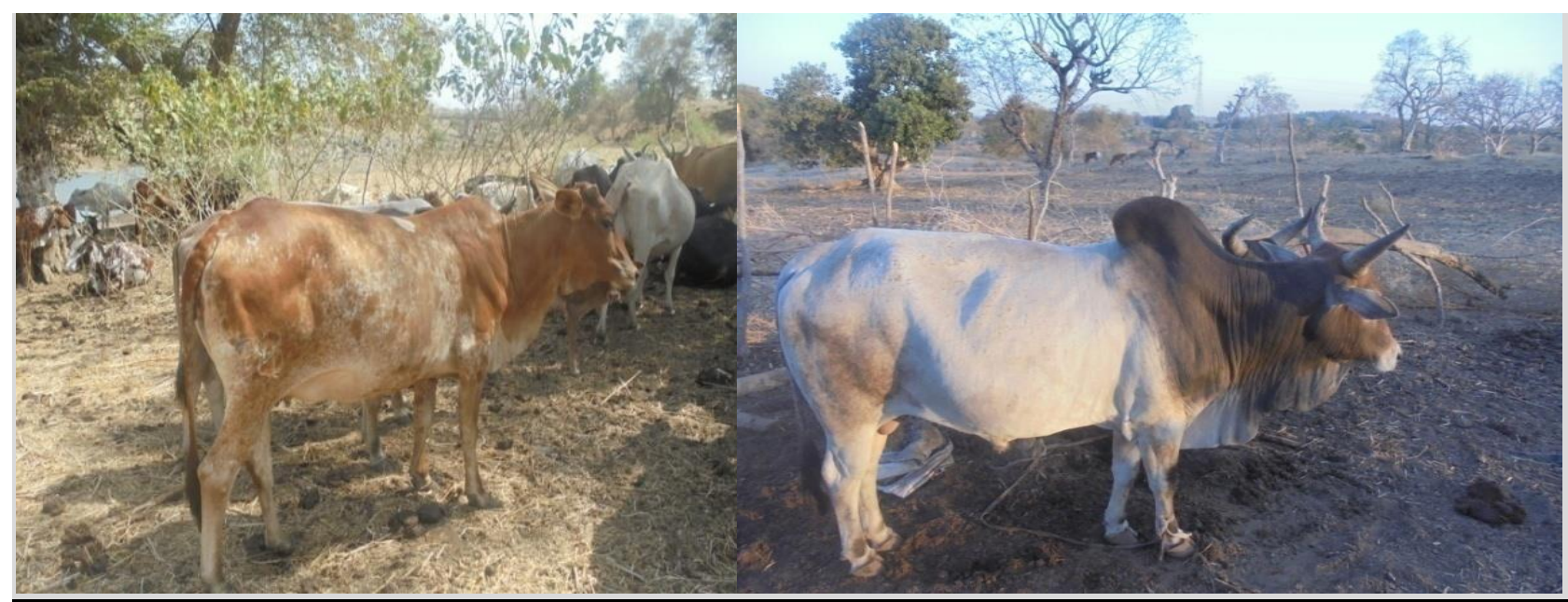

Figure 6 - Breeding female to the left and breeding male to the right in Qocherie cattle.

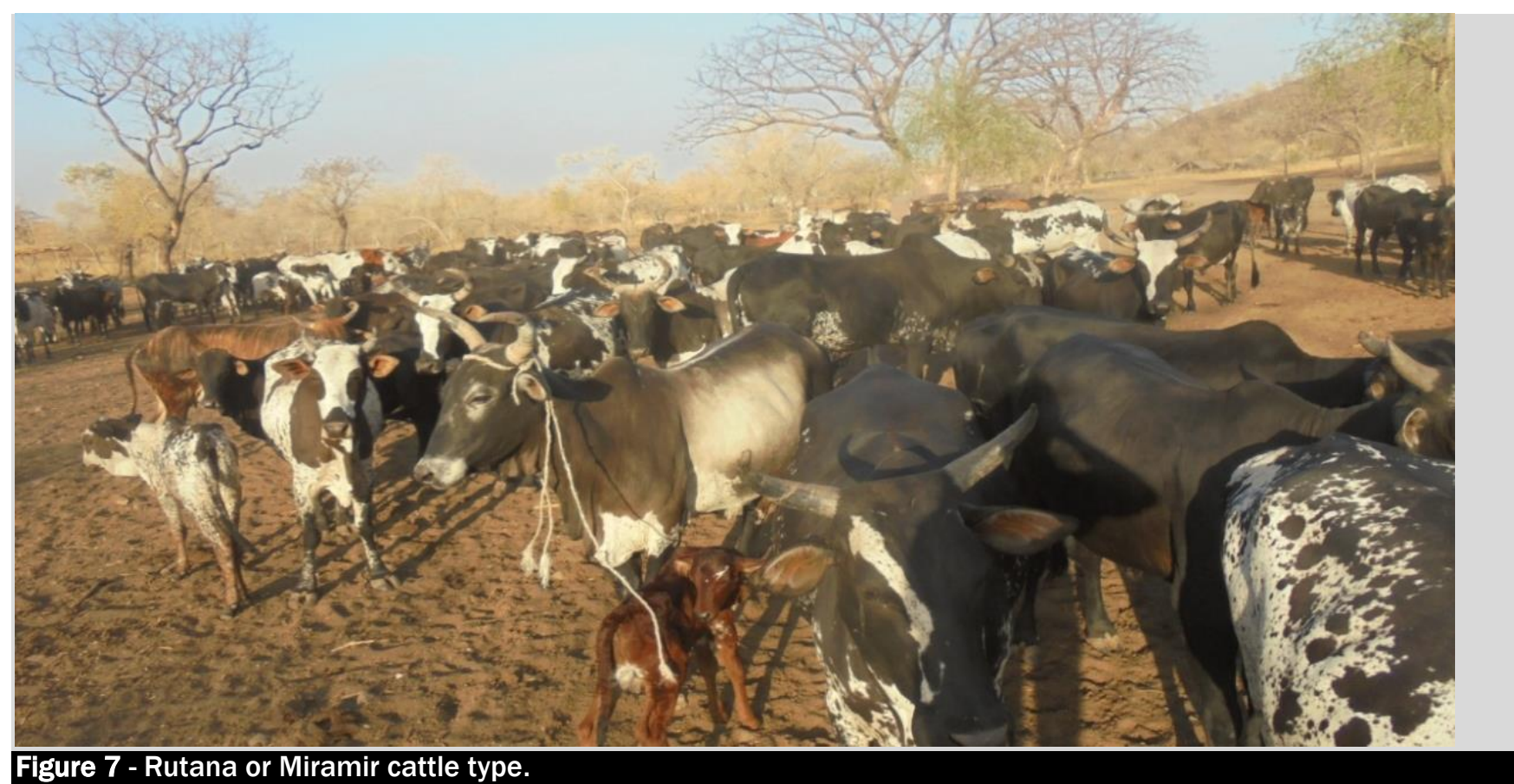



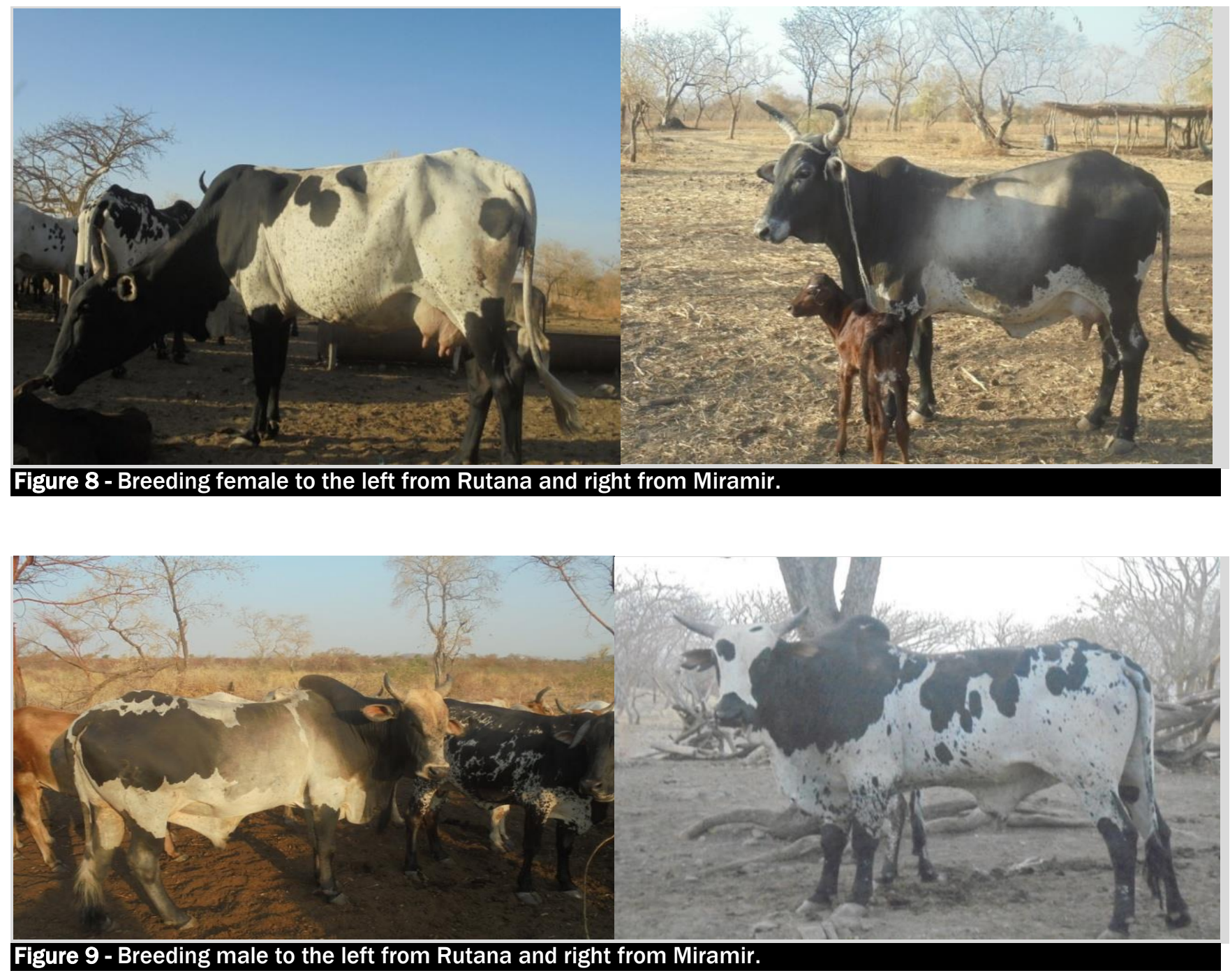

\section{CONCLUSION}

The key informant and focus group discussions are found to be a useful individual to identify distinct animal genetic resources of Qocherie/Korer, Fellata, Qocherie/Habesha, Rutana, Qocherie/Gobie and Miramir from the six sites of West Gondar zone. Phenotypically Fellata, Rutana and Miramir cattle had longer and larger body length, wither height, heart girth and pelvic width than Qocheire/korer/Gobie cattle types. In addition, characterization of the phenotypic diversity of cattle based on their morphologies, performances with univariate and multivariate analysis has given the powerful evidences on the general uniqueness of the three traditional cattle breed types (Qocherie/Korer/Gobie, Fellata and Rutana/Miramir).

\section{Recommendation}

The country, Amhara region and university of Gondar farm should try to introducing; Fellata and Rutana/Miramir cattle breed to on station characterization for breed improvement programs. Further, confirmatory and exploratory study should be employed other parts of Ethiopia to investigate the remaining cattle in the country. In-depth molecular characterization using genetic markers should be under taken to confirm the level of genetic variations and relationships among the identified and other indigenous cattle types in the country.

\section{DECLARATIONS}

\section{Corresponding Author}

E-mail: bele23@gmail.com

\section{Authors' Contribution}

All authors had similar role in writing and conducting of study.

\section{Conflict of interests}

The authors have not declared any conflict of interests. 


\section{REFERENCES}

CSA (2017). Agricultural Sample Survey. Report on livestock and livestock Characteristics, Volume II. Link I Google Scholar

DAGRIS (2009). Domestic Animal Genetic Resources Information System. Available at http://dagris.ilri.cgiar.org/display.asp ID=77 (seen on 15/01/2015).

Endashaw T (2010). Characterization of Mursi Cattle Breed In Its Production Environment, In Salamago Wereda, Southwest Ethiopia, M.Sc. Thesis, Haramaya University, Haramaya, Ethiopia. Link I Google Scholar

FAO (2010). Country Report Farm Animals Genetic Resources. Country Report Distribution and Roles of Livestock in Major Production System, Rome.

FAO (2012). Phenotypic characterization of animal genetic resources, Animal Production and Health Guidelines, No. 11. Rome. Link

Fasil G (2006). On-Farm Phenotypic Characterization of Cattle Genetic Resources and Their Production Systems in Awi, East and West Gojjam Zones of Amhara Region, Ethiopia. MSc Thesis Presented to the School of Graduate Studies of Alemaya Universit, p.131. Link I Google Scholar

Kemp S, Mamo Y, Asrat B, Dessie T. (2007). Domestic animal genetic resources information system. Addis Ababa: International Livestock Research Institute. Google Scholar

Mezgebe G, Gizaw S, Urge M (2018). Economic values of Begait cattle breeding-objective traits under low and medium input production systems in northern Ethiopia. Livestock Research for Rural Development. 30: Article \#12. Link I Google Scholar

Sasaki O, Takeda $\mathrm{H}$ and Nishiura A (2019). Estimation of the economic value of herd-life length based on simulated changes in survival rate. Animal Science Journal, 90: 323-332. Doi: https://doi.org/10.1111/asj.13158

Tadesse B (2015). On farm phenotypic characterization of indigenous cattle and their production systems in Bako Tibe and Gobu Sayo districts of Oromia Region, Ethiopia, M.Sc. Thesis, Haramaya University, Haramaya, Ethiopia. Link I Google Scholar

Tadesse T (2005). On-Farm Phenotypic Characterization of Cattle Genetic Resources and their Production Systems in South and North Wollo Zones of Amhara Region, North eastern Ethiopia, MSc Thesis Presented to the School of Graduate Studies of Alemaya University, p.111. Google Scholar

Zewdu W (2004). Indigenous cattle genetic resources, their husbandry practices and breeding objectives in North-western Ethiopia, An MSc Thesis Submitted to School of Graduate Studies, Alemaya University, Pp. 128. Link I Google Scholar 